ARTIGO

\title{
A CONSTRUÇÃO DO CONCEITO DE PRÁTICAS INFORMACIONAIS PELOS PESQUISADORES DO EPIC
}

\section{THE CONSTRUCTION OF THE CONCEPT OF INFORMATION PRACTICES BY EPIC RESEARCHERS}

\author{
Emanuelle Geórgia Amaral Ferreira ${ }^{1}$ \\ Flávia Ferreira Abreu ${ }^{2}$ \\ Gracirlei Maria Carvalho de Lima ${ }^{3}$ \\ Jéssica Patrícia Silva de Sá4
}

\begin{abstract}
${ }^{1}$ Mestra em Ciências da Informação pela Universidade Federal de Minas Gerais (UFMG).

E-mail: emanuelle.gaf@gmail.com

2 Mestra em Ciências da Informação pela Universidade Federal de Minas Gerais (UFMG). E-mail: flaviaabreu2911@gmail.com

${ }^{3}$ Mestra em Ciências da Informação pela Universidade Federal de Minas Gerais (UFMG). E-mail: leleygmc@gmail.com

${ }^{4}$ Mestra em Ciências da Informação pela Universidade Federal de Minas Gerais (UFMG). E-mail: j.jessicadesa@gmail.com
\end{abstract}

\section{ACESSO ABERTO}

Copyright: Esta obra está licenciada com uma Licença Creative Commons Atribuição 4.0 Internacional. $(\mathrm{cc}) \mathrm{EY}$

Conflito de interesses: A autora declara que não há conflito de interesses.

Financiamento: Não há.

Declaração de Disponibilidade dos dados: Todos os dados relevantes estão disponíveis neste artigo.

Recebido em: 24/04/2019.

Revisado em: 01/05/2019.

Aceito em: 10/05/2019.

\section{Como citar este artigo:}

FERREIRA, Emanuelle Geórgia Amaral; ABREU, Flávia Ferreira; LIMA, Gracirlei Maria Carvalho de; SÁ, Jéssica Patrícia Silva de. A construção do conceito de práticas informacionais pelos pesquisadores do EPIC. Informação em Pauta, Fortaleza, v. 4, n. especial, p. 26-43, maio 2019. DOI:

https://doi.org/10.0000/ip.v4iEspecial.2019.41 077.26-43

\section{RESUMO}

O objetivo deste trabalho é investigar como se deu a construção do conceito de Práticas Informacionais pelos pesquisadores do Grupo de Pesquisa Estudos em Práticas Informacionais e Cultura (EPIC). A pesquisa iniciou-se na disciplina "Usuários da Informação e Práticas Informacionais" do Programa de Pós-Graduação em Ciência da Informação (PPGCI) da UFMG, ministrada pela Professora Dra. Adriana Bogliolo Sirihal Duarte, no segundo semestre do ano de 2017. Ressalta-se que foi a última pesquisa desenvolvida pela docente, líder do Grupo EPIC, realizada coletivamente com os discentes durante sua última disciplina no PPGCI. 0 estudo foi realizado com pesquisadores do PPGCI/UFMG que defenderam seus trabalhos dentro da temática de estudos de Usuários da Informação e Práticas Informacionais. Como procedimento metodológico utilizou-se entrevistas semiestruturadas realizadas com sete pesquisadores. Nos resultados observou-se que as primeiras pesquisas sobre Práticas Informacionais não utilizavam essa terminologia, apresentando-se como estudos de usuários vinculados à abordagem social. Dessa 
forma, esse conceito foi se desenvolvendo à medida em que as pesquisas foram sendo realizadas no PPGCI. Identificou-se a atual compreensão dos pesquisadores sobre as Práticas Informacionais, além da diferenciação entre práticas e comportamento informacional. $\mathrm{Na}$ concepção dos estudos em Práticas Informacionais no grupo EPIC, evidencia-se a liderança da Profa. Dra. Adriana Bogliolo com o desenvolvimento do conceito e metodologias de pesquisa para investigação das Práticas Informacionais.

Palavras-chave: Práticas Informacionais. Usuários e usos da informação. Comportamento do usuário.

\section{ABSTRACT}

The objective of this work is to investigate how the concept of Informational Practices was developed by researchers from the Research Group on Informational Practices and Culture (EPIC). The research began in the discipline "Users of Information and Information Practices" of the Graduate Program in Information Science (PPGCI) of UFMG, taught by Doctor Adriana Bogliolo Sirihal Duarte, in the second half of 2017. It emphasizes it was the last research developed by the teacher, leader of the EPIC Group, held collectively with the students during his last discipline in the PPGCI. The study was conducted with researchers from the PPGCI/UFMG who defended their work within the theme of Information Users and Information Practices studies. As a methodological procedure we used semi-structured interviews with seven researchers. In the results it was observed that the first researches on Informational Practices did not use this terminology, being presented as studies of users linked to the social approach. Thus, this concept was developed as the research was carried out in the PPGCI. Identified the current understanding of the researchers on Informational Practices, as well as the differentiation between practices and informational behavior. In the conception of the studies in Informative Practices in the EPIC group, it is evident the leadership of Doctor Adriana Bogliolo with the development of the concept and research methodologies to investigate the Informational Practices.

Keywords: Information Practices. Users and uses of information. User behavior.

\section{INTRODUÇÃO}

O presente artigo apresenta uma pesquisa realizada pelos discentes do Programa de Pós- Graduação em Ciência da Informação (PPGCI) da Universidade Federal de Minas Gerais (UFMG) durante a disciplina nuclear da linha de pesquisa "Usuários, Gestão do Conhecimento e Práticas Informacionais" ofertada pelo PPGCI/UFMG: a disciplina “Usuários da Informação e Práticas Informacionais", ministrada pela Professora Dra. Adriana Bogliolo Sirihal Duarte, no segundo semestre do ano de 2017.

Tal pesquisa foi desenvolvida coletivamente pelos alunos com orientação efetiva da professora, com intuito de compreender melhor como estava sendo abordado e construído o conceito de Práticas Informacionais nas pesquisas de mestrado e doutorado do Programa de Pós-Graduação em Ciência da Informação (PPGCI/UFMG) no âmbito do Grupo de Pesquisa Estudos em Práticas Informacionais e Cultura (EPIC).

Liderado pela Professora Dra. Adriana Bogliolo Sirihal Duarte e pelo Professor Dr. Carlos Alberto Ávila Araújo, o grupo EPIC foi criado em 2013 e integrado ao Diretório de Grupos de Pesquisa do Conselho Nacional de Pesquisa (CNPq) em 2014. As atividades 
desenvolvidas pelo grupo objetivam a consolidação de uma nova perspectiva de estudar os sujeitos e suas relações com a informação, centrando no contexto social e cultural de cada indivíduo.

Assim sendo, a Professora Adriana nos apresentou o artigo sobre a historiografia do grupo EPIC (SIRIHAL DUARTE; ARAÚJO; PAULA, 2017). 0 artigo apresenta a relação das pesquisas de mestrado e doutorado sobre Práticas Informacionais desenvolvidas no âmbito do PPGCI/UFMG pelo grupo de pesquisa. Posteriormente, a professora orientou a formação de duplas de alunos, de forma que cada dupla pudesse selecionar uma das dissertações listadas no artigo, com intuito de que a pesquisa escolhida fosse estudada e apresentada para a turma. Dessa forma, sete dissertações foram analisadas e apresentadas pelos discentes, de forma que toda a turma pudesse conhecer os principais aspectos de cada pesquisa: objetivos, referencial teórico, metodologia adotada e análises de dados.

Após a análise do conceito de práticas informacionais presente nas pesquisas estudadas, a professora Adriana orientou a construção coletiva, em sala de aula, do roteiro de perguntas para realização de entrevistas semiestruturadas com os autores das pesquisas. 0 roteiro consistiu em onze perguntas para nortear a condução das entrevistas, que foram realizadas em outubro de 2017. Cada dupla entrevistou o autor da pesquisa que havia sido apresentada e analisada em sala. Foi elaborado também um Termo de Consentimento Livre e Esclarecido (TCLE), devidamente assinado pelos entrevistados.

Em um primeiro momento, as duplas realizaram a análise de suas respectivas entrevistas, criando categorias que abrangessem as temáticas abordadas pelos entrevistados. Depois, foi realizada uma segunda análise das entrevistas, dessa vez, com os alunos reorganizados em grupos pela professora. Dessa forma, cada grupo analisou três entrevistas diferentes, reavaliando as categorias de análise elencadas. Por fim, após a recategorização dos grupos, em sala de aula, chegou-se coletivamente às categorias gerais e definitivas para a análise de todas as entrevistas. A disciplina encerrou-se nessa etapa, com orientações da professora para a futura escrita de artigos com a apresentação dos resultados encontrados. Contudo, o adoecimento da professora no mês seguinte interrompeu os planos de dar prosseguimento à pesquisa.

Diante do exposto, como forma de homenageá-la, apresentaremos os resultados encontrados na categoria geral "concepção do conceito de Práticas Informacionais" 
desta que foi a última pesquisa conduzida pela Professora Dra. Adriana Bogliolo em sua última disciplina no PPGCI/UFMG.

Elencamos como objetivo geral deste trabalho: investigar como se deu a construção do conceito de práticas informacionais pelos pesquisadores do EPIC. Como objetivos específicos, buscou-se: compreender a visão dos pesquisadores sobre o conceito durante a pesquisa; entender a visão atual dos pesquisadores sobre o conceito; avaliar a construção do conceito pelos pesquisadores.

\section{CONTEXTUALIZANDO: OS ESTUDOS DE PRÁTICAS INFORMACIONAIS}

Embora a perspectiva de Práticas Informacionais se encontre no tradicional campo de "estudos de usuários da informação", os estudos sob tal ponto de vista vem com uma proposta de pesquisas voltadas para uma postura sociocultural, fazendo parte de um momento histórico de valorização do contexto nas investigações. A perspectiva das Práticas Informacionais, ainda em construção, apresenta novos aspectos para os estudos dos usuários, agora compreendidos como sujeitos informacionais, termo que ressalta o seu caráter de ator (SIRIHAL DUARTE; ARAÚJO; PAULA, 2017; SÁ, 2018).

\footnotetext{
As práticas informacionais consistem nos diversos modos como os sujeitos lidam com a informação, que nem sempre partem de uma necessidade específica, considerando-se o encontro ocasional com a informação. A busca e o uso da informação apresentam-se socialmente inseridos, permeados por processos comunicativos, que envolvem a interação entre os sujeitos e o compartilhamento de informações (SÁ, 2018, p. 36).
}

Dessa forma, essa perspectiva considera as relações dialógicas entre o sujeito e o contexto. A terminologia Práticas Informacionais denomina "os estudos conduzidos a fim de investigar como se dão os inter-relacionamentos entre o sujeito e a informação" (SIRIHAL DUARTE; ARAÚJO; PAULA, 2017, p. 3).

Os estudos de Práticas Informacionais concentram-se em compreender os indivíduos como membros de vários grupos e comunidades que constituem o contexto de sua vida e atividades cotidianas. A ênfase é no papel dos fatores contextuais que permeiam a busca, uso e compartilhamento de informações, o que difere das abordagens individualistas e descontextualizadas, como é o caso dos estudos de comportamento informacional. Nos estudos de comportamento informacional a informação é 
determinada por um fator externo e se ajusta às necessidades do indivíduo, desconsiderando o conjunto de fatores humanos, pessoais, individuais e coletivos que interferem na relação do sujeito com a informação. Os estudos de Práticas Informacionais levam em conta às características microssociológicas, propondo-se a olhar o micro para responder ao macrossocial (BERTI; ARAÚJO, 2017).

Berti e Araújo (2017) consideram que, nas investigações de Práticas Informacionais, a interação caracteriza a complexidade do sujeito, que pertence a dimensões individuais, coletivas, sociais, culturais e políticas. Assim, os contextos sociais também são influenciados a partir dessas relações. As Práticas Informacionais também podem lidar com elementos da comunicação e não apenas com a busca por informações. Desse modo, a fronteira entre comunicação e informação é difícil de ser delimitada, podendo sobrepor-se em muitos casos, como nos estudos de contextos interacionais de informação (SAVOLAINEN, 2007).

Rocha, Sirihal Duarte e Paula (2017) apresentam uma revisão do que poderíamos chamar de modelos teóricos de Práticas Informacionais empregados por diversos autores da Ciência da Informação. Os autores discutem a perspectiva de Savolainen (1995) que, mesmo não sendo um modelo efetivamente de práticas informacionais, é apontado como o precursor desses, pois contribui para os atuais estudos de práticas informacionais com a noção de vida cotidiana e a percepção de que a relação dos sujeitos com a informação é permeada de fatores sociais, culturais, individuais e temporais.

Na perspectiva apresentada por Savolainen (1995) há a quebra da sequência préconcebida de necessidade, busca e uso de informação dos tradicionais estudos de usos e usuários da informação. 0 autor enfatiza que a busca por informação é parte da vida cotidiana das pessoas. Assim, ele propõe um modelo de busca de informação na vida cotidiana (Everyday Life Information Seeking, ELIS). Outra perspectiva pontuada é o modelo bidimensional de práticas informacionais de McKenzie (2003). A autora adota o conceito de vida cotidiana proposto por Savolainen (1995), criando um modelo que considera as dimensões casuais envolvidas no processo de busca por informação. Para ela, o encontro casual com a informação tem a mesma importância de uma busca ativa.

Diante do exposto, a perspectiva das Práticas Informacionais recusa, portanto, a ideia de que a informação existe como objeto, independente do sujeito, e que estaria apenas à espera de ser acessada e utilizada. Pelo contrário, conforme esta abordagem é 
necessário que o sujeito social esteja em ação ao (res)significar o mundo fazendo uso do seu arsenal cultural.

Contudo, críticas à compreensão das Práticas Informacionais através de modelos são realizadas. Para Berti e Araújo (2017), teorias que embasam modelos valorizam os processos informacionais numa visão unidimensional do pensar, deixando de lado a compreensão de como os significados são construídos. Pois é dessa forma que são realizados os estudos de comportamento informacional, afastando-se as representações simbólicas presentes na interação social.

Assim sendo, no contexto dos estudos desenvolvidos sob a perspectiva das Práticas Informacionais, é preciso atentar para as ações, para aquilo que efetivamente se faz, sobretudo no cotidiano. É na prática, na ação do sujeito na sociedade, que é possível perceber como ele compreende a informação e como, criando um entendimento que é baseado tanto em sua experiência particular como em sua experiência coletiva, ele atua na sociedade na medida em que a expressão de sua interpretação também altera o cenário no qual está inserido.

\section{A CONSTRUÇÃO DO CONCEITO DE PRÁtICAS INFORMACIONAIS PELOS PESQUISADORES DO EPIC: RESULTADOS E DISCUSSÃO}

É de fundamental importância ressaltar que a pesquisa apresentou-se como um estudo em profundidade, cuja relevância está na variedade de dados encontrados, que abrangem a construção das pesquisas de modo completo, contendo informações sobre: a construção do conceito de Práticas Informacionais; a compreensão do conceito de sujeito informacional; a abordagem metodológica das pesquisas; a influência do orientador; o grau de satisfação com a pesquisa; os traços simbólicos do estudo; dentre outros aspectos. Como forma de realizar um recorte para o desenvolvimento desse artigo, optou-se por apresentar somente as categorias pertinentes à construção do conceito de Práticas Informacionais, visto que essa análise já foi completa o suficiente para promover uma ampla discussão.

Elencou-se três categorias de análise, em conformidade com os objetivos do presente trabalho: compreensão do conceito de Práticas Informacionais durante a 
pesquisa; concepção atual do conceito de Práticas Informacionais; e, Práticas Informacionais X Comportamento Informacional.

Destaca-se que o nome dos entrevistados foi mantido em sigilo, de forma a preservar os participantes da pesquisa, tal como explicitado no Termo de Consentimento Livre e Esclarecido (TCLE). Dessa forma, os pesquisadores foram identificados por E1, E2, E3, E4, E5, E6 e E7.

Quadro 1 - Pesquisas analisadas

\begin{tabular}{|c|c|c|}
\hline Temática & Método & Aporte Teórico \\
\hline $\begin{array}{l}\text { Descreve e analisa as práticas informacionais } \\
\text { das profissionais do sexo da zona boêmia de } \\
\text { Belo Horizonte. (SILVA, 2008). }\end{array}$ & $\begin{array}{l}\text { Coleta de dados: relatos, } \\
\text { entrevistas, com gravação em } \\
\text { áudio. Análise de dados: análise } \\
\text { de conteúdo. }\end{array}$ & $\begin{array}{l}\text { Práticas Informacionais; paradigma } \\
\text { social da CI }\end{array}$ \\
\hline $\begin{array}{l}\text { Busca compreender as práticas } \\
\text { informacionais de ouvintes assíduos de rádio } \\
\text { (PESSOA, 2010) }\end{array}$ & $\begin{array}{l}\text { Coleta de dados: relatos, } \\
\text { entrevistas, com gravação em } \\
\text { áudio. Análise de dados: análise } \\
\text { de conteúdo. }\end{array}$ & $\begin{array}{l}\text { Descrição densa de Geertz; } \\
\text { Dimensão emocional de Maffesoli. }\end{array}$ \\
\hline $\begin{array}{l}\text { Busca compreender como os idosos } \\
\text { percebem, descrevem e atribuem significado } \\
\text { à experiência da inclusão digital e seus } \\
\text { efeitos na vida diária, perpassando pelo } \\
\text { campo da sociabilidade e do comportamento } \\
\text { informacional. (GANDRA, 2012) }\end{array}$ & $\begin{array}{l}\text { Coleta de dados: entrevistas } \\
\text { semiestruturadas } \\
\text { profundidade, em } \\
\text { em áudio. Análise de dadcanão } \\
\text { análise de conteúdo. }\end{array}$ & $\begin{array}{l}\text { Abordagem social dos estudos de } \\
\text { usuários; Fenomenologia social de } \\
\text { Alfred Schutz. }\end{array}$ \\
\hline $\begin{array}{l}\text { Busca indícios de como a subjetividade } \\
\text { interfere no processo decisório, ou como os } \\
\text { aspectos subjetivos se integram às } \\
\text { competências individuais para influenciar } \\
\text { esse processo. Investigou o processo } \\
\text { decisório de bibliotecários durante a } \\
\text { atividade de indexação em bibliotecas } \\
\text { universitárias. (ARAÚJO, 2013) }\end{array}$ & $\begin{array}{l}\text { Coleta de dados: entrevista, } \\
\text { análise de tarefas, protocolo } \\
\text { verbal, aplicação do AT- } 9 . \\
\text { Análise de dados: análise de } \\
\text { conteúdo, análise do AT-9, } \\
\text { análise de símbolos. }\end{array}$ & $\begin{array}{l}\text { Abordagem clínica da informação. } \\
\text { Teste dos } 9 \text { arquétipos. }\end{array}$ \\
\hline $\begin{array}{l}\text { Investiga como pessoas com cegueira } \\
\text { congênita e adquirida interagem com a Web } \\
\text { e como percebem sua (in)acessibilidade, } \\
\text { buscando identificar as carências e } \\
\text { contribuições das Diretrizes de } \\
\text { Acessibilidade para o Conteúdo da Web } \\
\text { WCAG } 2.0 \text { para a construção de websites } \\
\text { mais adequados a esse perfil de usuários. } \\
\text { (ROCHA, 2013) }\end{array}$ & $\begin{array}{l}\text { Coleta de dados: entrevistas } \\
\text { semiestruturadas envolvendo } \\
\text { ensaios de interação, com } \\
\text { gravação de áudio e salvamento } \\
\text { das telas. Análise de dados: } \\
\text { análise de conteúdo. }\end{array}$ & $\begin{array}{l}\text { Abordagem social dos estudos de } \\
\text { usuários; Cognição Situada. }\end{array}$ \\
\hline $\begin{array}{l}\text { Investiga os elementos simbólico-afetivos } \\
\text { envolvidos no compartilhamento do } \\
\text { conhecimento na relação de orientação } \\
\text { estabelecida entre docentes e discentes de } \\
\text { um programa de pós-graduação stricto } \\
\text { sensu. (COELHO DE SÁ, 2015) }\end{array}$ & $\begin{array}{l}\text { Coleta de dados: entrevista, } \\
\text { análise de tarefas, protocolo } \\
\text { verbal, aplicação do AT-9. } \\
\text { Análise de dados: análise de } \\
\text { conteúdo, análise do AT-9, } \\
\text { análise de símbolos }\end{array}$ & $\begin{array}{l}\text { Gestão do conhecimento científico; } \\
\text { Teste dos } 9 \text { arquétipos; Abordagem } \\
\text { Clínica da Informação. }\end{array}$ \\
\hline $\begin{array}{l}\text { Analisa como as práticas informacionais de } \\
\text { mães de crianças com alergias alimentares } \\
\text { influenciam no dia-a-dia desses indivíduos. } \\
\text { (BARROS, 2016). }\end{array}$ & 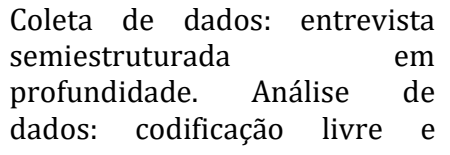 & $\begin{array}{l}\text { Práticas informacionais (Modelos } \\
\text { de Pâmela McKenzie e Yeoman). }\end{array}$ \\
\hline
\end{tabular}




\begin{tabular}{|l|l|l|}
\hline Temática & \multicolumn{1}{|c|}{ Método } & Aporte Teórico \\
\hline & $\begin{array}{l}\text { análise de conteúdo com grade } \\
\text { de categorias mista: a priori (a } \\
\text { partir do modelo de análise) e } \\
\text { liberdade de criação de novas } \\
\text { categorias. }\end{array}$ \\
\hline
\end{tabular}

Fonte: Adaptado de SIRIHAL DUARTE, ARAÚJO e PAULA (2017).

O quadro acima permite visualizar que a partir de 2008, a concepção do conceito Práticas Informacionais começa a ser introduzido nas pesquisas que buscam a compreensão da relação do sujeito informacional com as informações que demandam em seu cotidiano, por mais que o termo não se apresente diretamente nos títulos. Essa perspectiva é influenciada, sobretudo, pelo direcionamento que os orientadores passam para seus orientandos conforme podemos observar com as entrevistas.

\subsection{A Compreensão do conceito de práticas informacionais durante a pesquisa}

A presente categoria compreende o entendimento que os pesquisadores tinham do termo práticas informacionais à época de suas pesquisas de mestrado. Apresenta-se o conhecimento e/ou desconhecimento do conceito de práticas informacionais e apontamentos gerais dos entrevistados sobre o termo.

Quatro entrevistados definem suas pesquisas de mestrado como vinculadas à abordagem social dos estudos de usuários da informação. Observou-se que, no grupo EPIC, as primeiras pesquisas não utilizavam o termo práticas informacionais, já que o conceito ainda estava começando a ser estudado, de forma que as pesquisas se afirmavam pertencentes à abordagem social, promovendo uma ampliação da agenda do campo dos estudos de usuários da informação. Para os entrevistados, um estudo de Práticas Informacionais seria considerado mais profundo, uma vez que a utilização do termo abordagem social sugere um estudo mais amplo e menos específico.

E1: [...] eu não conhecia o conceito de práticas, e mesmo hoje conhecendo, eu penso que o conceito de práticas faz parte da abordagem social. Então era abordagem social, era o nome amplo da coisa, que eu tinha conhecimento naquele momento.

[...] Não, não chega a ser um estudo de práticas. [...] Eu acho que não chega. Eu acho que... Na análise que eu fiz assim eu não fui tão, tão profunda a ponto de chegar a ser práticas (grifo nosso). 
E2: Eu não conhecia o conceito com essa denominação de práticas informacionais. A gente falava da ampliação da agenda de estudos de usuários, fazia a relação com paradigma social naquela visão que Capurro falou sobre os paradigmas na Ciência da Informação e tinha a proposta de estudos dentro do paradigma social e de ampliar a agenda do campo de estudos de usuários, com abordagem compreensiva, mas não era usada essa denominação de práticas informacionais. Quando eu fiz a pesquisa a gente não falava, eu não tinha esse conhecimento com essa denominação de práticas informacionais.

E3: [...] na época a gente conversava muito sobre isso: olha e estou querendo pegar uma abordagem... Nós vamos pegar uma abordagem, então a gente trabalhou uma abordagem que seja mais de acordo com o paradigma social do Rafael Capurro. Que tem a abordagem tradicional que ela está muito ligada ao paradigma físico, as abordagens alternativas e da Brenda Dervin sensi-cognitivo, $e$ aí o [orientador] foi construindo o conceito [...] que era uma tentativa de ultrapassar essa ideia de comportamento.

O entrevistado E5, na ocasião da realização de sua pesquisa, a caracterizou como um estudo segundo a abordagem social, conforme os entrevistados acima mencionaram. No entanto, o entrevistado esclarece ainda que na ocasião da realização de sua pesquisa de mestrado, não havia discussão a respeito da concepção de Práticas Informacionais, embora ela fosse trabalhada, mas utilizando ainda o nome de abordagem social. Na fala abaixo, o entrevistado explicita que havia a concepção de que a abordagem social que trabalhavam no âmbito da pesquisa era diferente, mas ainda não havia sido denominada como Práticas Informacionais.

E5: Práticas mesmo, que eu me lembre, não tinha uma discussão, mais aprofundada não. Estava começando a se aprofundar numa discussão sobre a abordagem social dos estudos de usuários. E de alguma forma, também, aqui na Escola, com os meus professores que já trabalham com essa abordagem aqui na Escola, eu já percebia que era uma perspectiva, uma abordagem social diferente de como ela é trabalhada no cenário internacional. Mas, ainda assim era tentando fortalecer essa abordagem social. E assim, eu ouvia falar de práticas, mas não se sustentava, não fazia nenhuma construção em relação a isso. Eu defendi em 2012, então era assim em 2010 e 2011. Falava-se de abordagem social, práticas em algum momento, mas só de ouvir falar mesmo.

Contudo, a noção do conceito se ampliou e, hoje, o entrevistado E5 entende que a pesquisa desenvolvida sob a abordagem social dos estudos de usuários foi o nascedouro conceitual da perspectiva de Práticas Informacionais adotada atualmente.

E5: Eu me propus a fazer uma pesquisa conforme a abordagem social, mas hoje eu vejo que foi dali que começou a minha construção do que eu entendo do que é a perspectiva de práticas informacionais.

Assim como o E5, um dos entrevistados relatou que não conhecia o termo em profundidade à época de sua pesquisa. Ele afirma que, ao final da pesquisa, sugeriu-se 
que seu trabalho estaria relacionado aos estudos de usuários e ao conceito de Práticas Informacionais.

E7: Na época eu não conhecia o conceito em profundidade. Eu tinha já visto um conceito sobre o conceito de práticas informacionais durante a disciplina da Adriana de estudo de usuários que eu fiz no mestrado, e eu não lembro se eu estava no grupo de práticas, mas ele não tinha esse nome antes. [...] Eu sabia o que era, de certa forma sim, mas eu não consegui talvez na época, pensar na relação com minha pesquisa. [...] Depois não me lembro se foi no final, alguém leu minha pesquisa falou: "Olha isso aqui tem alguma coisa de estudo de usuários, que poderia ser, que poderia colocar."

O E3 também apontou pouco conhecimento sobre o conceito de Práticas Informacionais na época, mas que foi apresentada pelo seu orientador. 0 entrevistado também citou algumas referências que deram base para ele ir a campo e compreender como se dava a busca de informação no cotidiano do seu universo de pesquisa. Além disso, ele pontuou que o conceito estava sendo construído e citou a obra de Regina Marteleto (MARTELETO, 1995) como base para o seu referencial teórico.

E3: Foi tudo indicação do [orientador] mesmo. Foi um livro que eu li na época, uma pesquisa do Hermano Vianna sobre o funk carioca. Olha! Essa pesquisa do Hermano você não precisa compreender o conteúdo da antropologia. Ele me disse "capítulo muito técnico, mas eu quero que você entenda o trabalho de campo dele, a descrição a narrativa, de como ele entendeu o campo, como ele escreveu a abordagem do objeto". Então assim é muito bom, não foi usado na minha dissertação, mas foi um livro que foi importante porque o Hermano fez uma profunda análise do espaço prático dele, o que ele fazia no Rio na década de 80. Ele ia aos bailes, ele emergia para depois fazer a descrição do era que ele queria que era relação daquela pessoas com funks.

E3: É porque assim... Eu tenho que lembrar aqui porque é eu trabalhei com um conceito que estava presente na obra da Regina Marteleto[...] Na época ela não tinha um conceito claro. Foi um conceito que estava sendo construído ainda. A própria obra dela na época não tinha tudo muito claro, ela vinha com a ajuda do [orientador] que era uma tentativa de ultrapassar essa ideia de comportamento.

Assim como o E3, o E5 pontuou que não tinha conhecimentos suficientes à época da realização de sua pesquisa. Afirmou que na ocasião, não relacionou Práticas Informacionais como uma perspectiva que poderia ser considerada como estudos da abordagem social.

E5: Eu acho que se eu tivesse escutado antes, ou bem no inicinho do mestrado e atrelasse esse termo à abordagem social dos estudos de usuários, talvez eu tivesse utilizado. Mas, como foi no meio e realmente, assim, não tinha uma compreensão do que era, se era exatamente a mesma coisa de uma abordagem social ou não.

Conforme podemos observar, a compreensão da concepção de Práticas Informacionais se iniciou a partir da vinculação dos estudos de usuários realizados com 
a abordagem social. Os entrevistados, embora não nomeassem as pesquisas como estudos de Práticas Informacionais, identificaram na ocasião que se tratava de pesquisas com um viés mais amplo do que concebiam os estudos sob a abordagem social da época.

\subsection{Concepção atual do conceito de práticas informacionais}

Essa categoria apresenta a concepção atual que os pesquisadores possuem sobre o conceito de práticas informacionais.

Uma parte dos entrevistados prosseguiu com atividade de pesquisa, realizando o doutorado. Percebe-se que esse grupo amadureceu as suas concepções sobre práticas informacionais, elaborando melhor o conceito.

E1: Na tese eu assumi práticas. Apesar de eu ter certeza do que não é práticas. $O$ que é práticas eu ainda estou descobrindo, mas eu já assumo termos e quero levar isso até... Inclusive tendo uma discussão teórica um pouco mais aprofundada do que eu fiz na dissertação (grifo nosso).

E5: Práticas informacionais estaria dentro da abordagem social dos estudos de usuários, talvez, e que essa abordagem tenta entender o sujeito como um ser histórico, cognoscente e que ele é conformado, constituído pelos referenciais sociais. Então, as suas ações, suas ideias, elas são resultados da intersubjetividade presente na sociedade.

E7: E as práticas, elas para mim são as percepções da pessoa mesmo, do sujeito, em relação tanto à realidade dele, quanto também as questões culturais e sociais. Mas eu acho que as práticas, elas entram mais na parte subjetiva do estudo de usuários. Pensando assim, chamando de estudo de usuários, a questão das práticas informacionais, mas acho que as práticas elas eram mais na parte subjetiva dos usuários, mas que também tem um foco nas interações entre os usuários.

No entanto, é notório que o conceito de práticas informacionais ainda é incipiente, não havendo um consenso sobre sua definição. Até mesmo o uso da terminologia é questionado, visto que as Práticas Informacionais podem ser consideradas um conceito ou uma perspectiva, dependendo do ponto de vista de cada pesquisador.

E1: É uma coisa um tanto quanto controversa assim, eu acho que o conceito ainda é incipiente, na verdade eu não... Eu tendo a não ver práticas como conceito, eu tendo a ver práticas como uma perspectiva, uma forma de olhar. Eu tenho um pouco de dificuldade assim de definir práticas conceitualmente falando, eu acho que é uma coisa muito fluida assim pra, pra você criar um conceito, comportamento é mais... Porque passa aquela ideia de mais visível, práticas me passa uma coisa mais fluida, então eu prefiro ver como uma perspectiva. E aí a 
diferença que eu vejo é a forma como você analisa, a forma como você olha pra aqueles dados.

Identificou-se nos discursos dos entrevistados que os estudos de Práticas Informacionais são vinculados à pesquisa de uma coletividade, na análise da interação de um grupo de pessoas.

E1: Porque eu vejo e práticas mais como o estudo de um coletivo de pessoas que têm algum vínculo algum tipo de interação em comum. Posso estar equivocada, mas para mim, prática fica mais, mais visível neste sentido da coletividade. [...] E para fazer práticas eu acho que o estudo fica mais interessante com um grupo que interage mais frequentemente, pode ser virtualmente inclusive, não precisa ser presencialmente, mas que tenha uma construção conjunta; ou desconstrução.

E7: [...] partindo desse meu "pré concebimento" das práticas, tem muito foco nas interações tanto sociais quanto dessa realidade mesmo entre as pessoas.

Seguindo a concepção de que os estudos de Práticas Informacionais são voltados a pesquisas com a interação de grupos de pessoas, E6 pontua que nesse sentido, os sujeitos informacionais da pesquisa são vistos do ponto de vista de atores sociais realmente ativos em sua interação com a informação.

E6: Eu percebo as práticas informacionais como esse momento de sujeitos mais ativos, de sujeitos mais complexos ao tratar com a informação, então eles têm um senso crítico, eles têm percepções.

Existe também a concepção de que um estudo de Práticas Informacionais necessita de outra teoria para ser operacionalizado.

E1: [...] exatamente porque eu falei que eu acho práticas uma coisa muito fluida e eu preciso de uma teoria já estabelecida para operacionalizar a coisa.

O grupo EPIC apresenta-se como uma referência para o estudo das Práticas Informacionais, pois direciona leituras e discussões sobre a temática. Entretanto, é reconhecida a multiplicidade de ideias entre os pesquisadores do grupo, de forma que não há unanimidade no entendimento do conceito.

E1: Eu acho que muita coisa tem uma influência do grupo. Eu às vezes assim, apesar do grupo não ter uma, uma unanimidade no que se entende de práticas (às vezes eu tenho a sensação que cada um entende uma coisa diferente), mas eu acho que é importante porque direciona um pouco; mesmo não tendo um consenso, direciona. Apesar de às vezes eu achar que eu tenho um entendimento de práticas, de práticas informacionais, um pouco mais distinto do grande... do que o grupo tem [...].

E7: [...] eu lembro que estava no início das discussões, acho que em 2015 mesmo que talvez eu tenha começado a participar do grupo. Estava sendo uma coisa de 
estudo de usuários, de comportamento informacional, tinha uma discussão sobre conceitos, então esse conceito ele não estava muito claro para mim ainda [...].

Tanto que o entrevistado E4 não usou o conceito de Práticas Informacionais em sua dissertação e, atualmente, já no doutorado, também não se sente seguro em usar a conceituação em sua pesquisa.

E4: A complexidade da minha pesquisa não pede que eu entre com um conceito que pra mim é novo, sem ter o domínio dele. Tanto que eu também não uso no doutorado. Hoje não me sinto confortável pra usar isto.

No discurso de E1 foi presente a citação de vários autores, principalmente suecos, que se dedicam a pesquisas sobre Práticas Informacionais.

E1: Tem uma autora da Suécia que ela fala que a prática informacional é meio que corporificada e eu tendo a concordar com isso sabe. [...] Ela chama Harlan, tem a Isah e a Harlan. Elas usam esse termo pra falar que é quase que corporificada assim nas ações do dia-a-dia. Então eu acho que é uma forma de agir meio que inconsciente e meio que sem uma, um start assim, tipo você tem essa necessidade vai lá e busca.

[...] Porque acaba que eu vou sendo influenciada pela percepção e eles [autores da Suécia] falam inclusive [de] um estudo sobre as; pelas lentes das práticas, então quando eu falo que práticas para mim é uma perspectiva eu acho que é mais pela influência deles. É porque eles também entendem práticas como uma forma de ver uma determinada realidade e não como um conceito. Então eu acho que talvez seja uma influência dessas leituras.

Consonante com o posicionamento de Berti e Araújo (2017), o E6 apontou que os estudos desenvolvidos sob a perspectiva das Práticas Informacionais não se adéquam a um modelo específico de pesquisa. Trata-se de estudos com enfoques socioculturais que não se devem se limitar a modelos ou a uma representação gráfica.

E6: Eu acho interessante para isso, assim, perceber o quanto que, por mais que a gente tente colocar numa tabela, colocar num gráfico, num quadro, é, essas questões das práticas, elas são muito, muito mais complexas do que a gente possa imaginar, é praticamente impossível a gente colocar isso bonitinho, né, num quadro, aqui, num modelo.

Outra parte do grupo de entrevistados não prosseguiu com a atividade de pesquisa, voltando-se para o mercado de trabalho. Essas pessoas, que distanciaram-se da academia, percebem que os conceitos evoluíram, contudo não souberam especificar como os compreendem atualmente.

E2: Eu acho que as terminologias, os conceitos foram mudando e se ampliando com o tempo e refletindo essa nova compreensão e abrangência. [...] Eu acabei me afastando dos estudos e não acompanhando essas novas terminologias. Depois do mestrado eu no mercado de trabalho não estou tendo tanta oportunidade de 
contato com esses campos que estão se ampliando, mas eu acredito que as novas terminologias dão mais a real dimensão dessa abrangência, maior do que está sendo feito na área.

E3: Olha! Como eu disse... como eu estou por fora das mudanças da área, talvez é só uma evolução do conceito de prática, né? E como eu disse antes também, quanto à leitura especialmente nessas áreas, assim, mais novas... a literatura está muito... Tem muita literatura norte-americana, talvez o conceito já tivesse bem trabalhado lá [na época da pesquisa]. Então assim, o que eu talvez... se fosse aplicar hoje, se fosse mudar... Tivesse algum conhecimento da área hoje é seria uma evolução desse conceito de prática [...] deve ter incorporado muita coisa nova. Então assim eu queria ter me aprofundado mais nesse conceito de prática para deixar a dissertação é... mais forte, eu ter ... sei lá... Eu acho que ela... Mais força para ir a eventos da área.

A maioria dos pesquisadores continuaram suas pesquisas iniciadas no mestrado em um doutorado. Entre esses pesquisadores, podemos perceber de um lado, o aprofundamento do conceito da perspectiva dos estudos em Práticas Informacionais por alguns doutorandos em suas respectivas pesquisas. Por outro lado, pouca identificação conceitual e insegurança para usar o conceito por parte de alguns pesquisadores de doutorado; fato que também ocorreu com aqueles que se afastaram do meio acadêmico e, por conseguinte, do grupo EPIC, para se dedicarem ao mercado de trabalho.

Nota-se que parte dos pesquisadores adotou o conceito de Práticas Informacionais em suas pesquisas atuais, devido ao aprofundamento da perspectiva com relação ao período inicial das pesquisas de mestrado. Há ainda um entendimento de que as Práticas Informacionais são uma perspectiva de pesquisa, vinculada a abordagem social de estudos de usuários da informação. Contudo, não há um consenso terminológico por parte do grupo EPIC, uma vez que alguns adotam o termo conceito no lugar de perspectiva.

Atualmente, é perceptível o consenso dentre os pesquisadores investigados da concepção de sujeito informacional no âmbito dos estudos de Práticas Informacionais, abandonando o termo usuários da informação por considerar além dos aspectos cognitivos, os aspectos históricos e socioculturais nas pesquisas.

\subsection{Práticas Informacionais X Comportamento Informacional}

Nessa categoria apresentam-se as comparações e diferenciações entre os conceitos de práticas informacionais e comportamento informacional. 
Nos discursos dos entrevistados identificou-se uma tentativa de fazer uma distinção entre os dois conceitos, uma vez que ambos estão vinculados aos estudos de usuários da informação. Contudo, os conceitos vinculam-se a diferentes vertentes dentro desse campo.

E1: Eu posso tá equivocada, mas eu penso da seguinte forma, estudos de usuários é uma subárea da Ciência da Informação... E estudo de práticas e de comportamento? São vertentes possíveis de se fazer dentro dos estudos de usuários, então um estudo de práticas ele é um estudo de usuários, só que ele pega uma vertente, que é a vertente de práticas, da mesma forma o de comportamento informacional.

E6: [...] o estudo de comportamento informacional, que também já é mais antigo, o estudo de práticas já é mais recente do que o de comportamento, né, mas o estudo de comportamento informacional está mais voltado para um usuário que é mais estático, é um usuário que não é percebido como um ser tão evoluído quanto o da prática informacional. No da prática, o usuário é visto como um ser atuante, que sofre interferência do ambiente, das pessoas, mas também interfere, né, então, ele já é mais para o tipo de estudo que eu tenho a ver, que estou relacionada, dentro da Comunicação mesmo, que percebe o ser como um ser ativo [...].

E7: Do comportamento informacional, eu acho que ele pauta mais na cognição do usuário né? E que seria talvez assim, como que ele se comporta diante da informação. Para mim eu acho que seria mais ou menos isso essa diferença de estudo de usuários para comportamento. E as práticas, elas para mim são as percepções da pessoa mesmo, do sujeito, em relação tanto à realidade dele, quanto também as questões culturais e sociais. [...] E sendo que os outros, são muito focados no aprofundamento da melhoria do sistema, talvez os estudos de usuários, o comportamento acho que não tem muito essa interação entre os usuários né? Acho que é isso.

O entrevistado E1 mostrou certa resistência ao pensar em fazer um estudo utilizando o conceito de comportamento informacional.

E1: Olha, a única certeza que eu tinha é que eu não queria fazer estudo da abordagem cognitiva ou alternativa, sabe, eu já, apesar de tá há pouco tempo na área, eu já via que não era aquilo que eu queria, eu queria um pouco além.

[...] Eu tendo a achar que eu aproximei mais de práticas. Eu evitei comportamento conscientemente. Eu não queria fazer um estudo de comportamento informacional; é um tema que eu tenho uma certa resistência.

$\mathrm{Na}$ visão dos pesquisadores, o conceito de Práticas Informacionais mostra-se mais profundo do que o conceito de comportamento informacional.

E1: E eu acho que práticas ela aprofunda um pouco mais do que comportamento. Sabe, assim a sensação que eu tenho é... O comportamento ele tem uma motivação mais sei lá, a lacuna, acho que é até lugar comum ficar repetindo isso, mas o comportamento ele parte de uma lacuna, a prática ela já é mais cotidiana e eu não tô falando só de informação pra vida cotidiana, tô falando de forma geral, é meio que uma coisa incorporada... Incorporada sei lá, é uma coisa que a pessoa não tá... Porque o comportamento, eu vejo da seguinte forma, quando se fala de comportamento informacional, você tem uma necessidade, você se levanta vai lá 
faz uma busca, planejada, meio que uma sequência de passos. E a prática é como se ela tivesse diluída no dia-a-dia [...].

E2: Eu acredito que estudos de usuários da informação surgiram muito relacionados à visão mais positivista, mais pragmática, mais relacionada a grupos específicos de usuários de sistemas de informação e eu acredito que esses novos termos tem uma abrangência maior do que é feita agora.

Podemos observar a tentativa dos pesquisadores entrevistados em diferenciar os estudos de Comportamento Informacional de estudos dedicados a concepção de Práticas Informacionais. Há um claro consenso sobre as diferenças e finalidades de cada um dos estudos. Embora façam parte dos estudos de usuários da informação, Comportamento Informacional é um estudo conforme a abordagem cognitiva e Práticas Informacionais é um estudo conforme a abordagem social. Os entrevistados frisaram que os estudos sob a ótica das Práticas Informacionais são mais abrangentes, além de dar mais ênfase ao protagonismo do sujeito e sua interação com a sociedade.

\section{CONCLUSÃO}

Com a realização desta pesquisa, podemos constatar como se deu a constituição do conceito da perspectiva das Práticas Informacionais no âmbito do grupo EPIC. A criação do grupo EPIC se deu em 2013, sendo consolidado por meio do cadastro no CNPq em 2014. Mas muito antes, a maneira de olhar para os sujeitos informacionais por meio da abordagem social de estudos de usuários realizada em vários trabalhos de pesquisa de membros do grupo EPIC, já transmitia a diretriz do que viria.

Conforme podemos observar, os estudos realizados no âmbito das Práticas Informacionais iniciaram vinculados à abordagem social e se mantém até então. Alguns pesquisadores adotaram o termo inicialmente, outros utilizaram "comportamento informacional" mesmo compreendendo que o escopo de sua pesquisa havia sido mais amplo. Contudo, o conceito de Práticas Informacionais foi sendo fundamentado a medida que as pesquisas de mestrado foram se desenvolvendo e esses pesquisadores foram dando continuidade no doutorado. Desde o princípio, a perspectiva das Práticas Informacionais foi concebida de maneira a perceber o sujeito informacional como protagonista da ação informacional, compreendendo que trata-se de um indivíduo cognoscente que busca por informação de maneira natural, cotidianamente, que tem sua 
cultura, história, que interage com meio, influencia e é influenciado. Portanto, o sujeito estudado nos estudos de Práticas Informacionais é visto em conformidade com o seu contexto sociocultural, não somente em seu aspecto cognitivo como nos estudos de Comportamento Informacional.

Destaca-se o protagonismo da Profa. Dra. Adriana Bogliolo Sirihal Duarte na liderança do grupo e das pesquisas em torno das Práticas Informacionais. Profa. Adriana é uma das responsáveis pela consolidação do conceito e adoção de algumas das metodologias utilizadas na perspectiva de Práticas Informacionais desenvolvidas no âmbito do grupo EPIC. Ela tinha o dom didático para categorizar os dados que permitia uma compreensão mais efetiva das pesquisas. Uma profissional apaixonada que buscava sempre inovar e levava consigo generosamente docentes e discentes que ousavam alçar vôos mais altos. Essa pesquisa foi a última pesquisa desenvolvida coletivamente por ela e por discentes em sua última disciplina no PPGCI/UFMG. Mais uma contribuição para a compreensão dos conceitos que o grupo EPIC está construindo.

\section{REFERÊNCIAS}

ARAÚJO, Eliane Pawlowski Oliveira. Tomada de decisão organizacional e subjetividade: análise das dimensões simbólico-afetivas no uso da informação em processos decisórios. 2013. 165f. Dissertação. (Mestrado em Ciência da Informação) - Universidade Federal de Minas Gerais, Belo Horizonte, 2013.

BARROS, Flávia Moraes Moreira.

Protagonismo nas práticas informacionais de mães de crianças alérgicas. 2016. 186 f. Dissertação. (Mestrado em Ciência da Informação) Universidade Federal de Minas Gerais, Belo Horizonte, 2016.

BERTI, Ilemar Christina Lansoni Wey; ARAÚJO, Carlos Alberto Ávila. Estudos de usuários e práticas informacionais: Do que estamos falando?. Informação e

Informação, Londrina, v. 22, n. 2, p. 389 401, maio/ago., 2017. Disponível em: http://www.uel.br/revistas/uel/index.php/i nformacao/issue/view/1320. Acesso em: 4 abr. 2019.
COELHO DE SÁ, Rosilene Moreira.

Compartilhamento do conhecimento e o processo de orientação de discentes de pós-graduação stricto sensu. 2015. $158 \mathrm{f}$. Dissertação. (Mestrado em Ciência da Informação) - Universidade Federal de Minas Gerais, Belo Horizonte, 2015.

GANDRA, Tatiane Krempser. Inclusão digital na terceira idade: um estudo de usuários sob a perspectiva fenomenológica. 2012. 137 f. Dissertação (Mestrado em Ciência da Informação) - Universidade Federal de Minas Gerais, Belo Horizonte, 2012.

MARTELETO, Regina Maria. Cultura informacional: construindo o objeto informação pelo emprego dos conceitos de imaginário, instituição e campo social. Ciência da Informação, Brasília, v.24, n.1, p. 89-93, jan./abr. 1995.

MCKENZIE, Pamela. A model of information practices in accounts of everyday - life information seeking. Journal of Documentation, v. 59, n. 1, p. 19-40, 2003. 
PESSOA, Marina Torres. A relação entre ouvintes assíduos e o rádio: um estudo de usuários da informação a partir de uma perspectiva compreensiva. 2010. $95 \mathrm{f}$. Dissertação. (Mestrado em Ciência da Informação) - Universidade Federal de Minas Gerais, Belo Horizonte, 2010.

ROCHA, Janicy Aparecida Pereira. (In) Acessibilidade na web para pessoas com deficiência visual: um estudo de usuários à luz da Cognição situada. 2013. 160 f. Dissertação (Mestrado em Ciência da Informação) - Universidade Federal de Minas Gerais, Belo Horizonte, 2013.

ROCHA, Janice Aparecida Pereira; SIRIHAL DUARTE, Adriana Bogliolo; PAULA, Claudio Paixão Anastácio de. Modelos de práticas informacionais. Em Questão, v. 23, p. 36-61, 2016. Disponível em: https://seer.ufrgs.br/EmQuestao/article/vie w/67014/39098. Acesso em 4 abr. 2019.

\section{SÁ, Jéssica Patrícia Silva de. Ler e} compartilhar na web: práticas informacionais de blogueiros literários. 2018. 241 f. Dissertação (Mestrado em Ciência da Informação) - Escola de Ciência da Informação, Universidade Federal de Minas Gerais, Belo Horizonte, 2018.
SAVOLAINEN, Reijo. Everyday Life Information Seeking: Approaching Information Seeking in the Context of "Way of Life". Library \& Information Science Research, Amsterdam, v. 17, p. 259-294, 1995.

SAVOLAINEN, Reijo. Information behavior and information practice: reviewing the "umbrella concepts" of information-seeking studies. Library Quarterly, Chicago, v. 77, n. 2, p. 109-132, 2007.

SILVA, Ronaldo. As práticas informacionais das Profissionais do Sexo da zona boêmia de Belo Horizonte. 2008. 171 f. Dissertação. (Mestrado em Ciência da Informação) Universidade Federal de Minas Gerais, Belo Horizonte, 2008.

SIRIHAL DUARTE, Adriana Bogliolo; ARAUJO, Carlos Alberto Ávila; PAULA, Cláudio Paixão Anastácio de. Práticas informacionais: desafios teóricos e empíricos de pesquisa. In: Encontro Internacional de Usos e Usuários da Informação, 1., Fortaleza. Anais... 2017. Disponível em: http://www.eneu2017.ufc.br/index.php/ene u/1/paper/viewFile/60/31. Acesso em: 4 abr. 2019. 